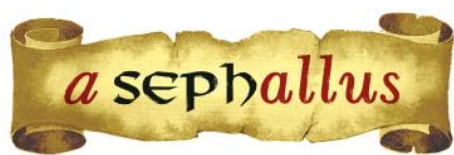

Revista aSEPHallus de Orientação Lacaniana

Núcleo Sephora de Pesquisa sobre o Moderno e o Contemporâneo

ISSN 1809 - 709 X

\title{
A psicanálise é politicamente revolucionária ou conservadora? ${ }^{1}$
}

Tania Coelho dos Santos

Pós-doutorado no Departamento de Psicanálise de Paris VIII (Paris, França) Professor Associado, nível IV no Programa de Pós-graduação em Teoria Psicanalítica/UFRJ (Rio de Janeiro, Brasil)

Pesquisadora do CNPQ nível 1 C (Brasil)

Presidente do Instituto Sephora de Ensino e Pesquisa de Orientação Lacaniana/ ISEPOL (Rio de Janeiro, Brasil)

Psicanalista Membro da École de La Cause Freudienne, da Escola Brasileira de Psicanálise e da Associação Mundial de Psicanálise Membro da Associação Universitária de Pesquisa em Psicopatologia Fundamental (Brasil) E-mail: taniacs@openlink.com.br

\begin{abstract}
Resumo: Em que medida o espírito, o gosto e o apelo revolucionário podem ser classificados em conformidade com a relação que manifestam ao real enquanto impossível? Qual é o lugar que o conceito de revolução pode ocupar no nosso campo? A pulsão de morte, o real, o trauma, a angústia, a violência, a feminilidade, por exemplo, são conceitos que apontam para uma disposição potencialmente revolucionária que habitaria a esfera mais íntima de cada um? Haveria um pathos revolucionário, que algum destes conceitos permite abordar? A travessia do fantasma, a reiteração do sinthoma como resto de uma análise, testemunhariam o pathos revolucionário do processo analítico? O que é que define um pensamento e uma ação política de direita ou de esquerda? Parto da premissa de que a referência central que as distingue é o conceito de revolução.
\end{abstract}

Palavras-chave: revolução; psicanálise; real; direita; esquerda; ação política.

\section{La psychanalyse est politiquemente revolucionnaire où conservatrice?}

Dans quelle mesure l'esprit, le goût, l'appel révolutionnaire peut être classé en fonction de la relation qu'ils manifestent avec le réel comme impossible? Quelle est la place que le concept de révolution peut prendre dans notre domaine? La pulsion de mort, le réel, le traumatisme, l'angoisse, la violence, la féminité, par exemple, sont des concepts qui pointent vers une humeur potentiellement révolutionnaire qui peuplent la sphère la plus intime de chacun? Existerait-il un pathos révolutionnaire, que certains de ces concepts permettent d'adresser? La traversée de fantôme, la réitération du sinthome comme reste d'analyse, témoigneraient-ils du pathos révolutionnaire du processus analytique? Qu'est-ce qui définit une pensée et une action politique comme étant de droite ou de gauche? Je pars de la prémisse selon laquelle la référence centrale qui les distingue est le concept de révolution.

Mots-clés: révolution; psychanalyse; réel; droite; gauche; action politique.

\section{The psychoanalysis is policalilly revolutionary or conservative?}

To what extent can the spirit, the taste, the revolutionary appeal be classified according to the relation they manifest to the real as impossible? What is the place that the concept of revolution can occupy in our field? Are the death drive, the real, the trauma, the anguish, the violence, the femininity, for example, concepts that point to a potentially revolutionary disposition that would inhabit the innermost sphere of each one of us? Would there be a revolutionary pathos, which one of these concepts allows to approach? The crossing of the phantasme, the reiteration of the sinthome as the rest of an analysis, would witness the revolutionary pathos of the analytic process? What defines right-wing or left-wing political thinking and action? I start from the premise that the central reference that distinguishes them is the concept of revolution.

Keywords: revolution; psychoanalysis; real; right; left; political action. 


\title{
A psicanálise é politicamente revolucionária ou conservadora?
}

\author{
Tania Coelho dos Santos
}

As manifestações de psicanalistas nas redes sociais, durante os acontecimentos políticos de nossa história política recente, me impeliram a ensaiar uma reflexão acerca do pensamento psicanalítico sobre o laço social à luz da seguinte questão: é de esquerda ou de direita? A psicanálise é uma ciência, uma prática, uma ética, uma ideologia ou um discurso? Alguma dessas definições justificaria defini-la como revolucionária? Se alguma dessas dimensões revela que ela é revolucionária, como reconhecer a relação ao real que evidencia esta vocação? No mínimo, ela se manifestaria mais vivamente nos analistas que concluíram suas análises. Haveria um pathos propriamente revolucionário inerente à relação do analista ao real?

Nos últimos anos ${ }^{2}$, tenho insistido muito em dizer que é preciso, urgentemente, esclarecer de que teoria do real nos servimos na psicanálise hoje, seja para ensiná-la enquanto um corpo de ferramentas conceituais e clínicas, seja para transmitir aquilo que não se pode ensinar, o saber fazer do psicanalista ${ }^{3}$. Para isto, não se pode desconsiderar as diferentes dimensões em jogo neste campo. Como em qualquer ciência, existe na psicanálise o esforço de formalização do real ao qual ela se refere. Como em qualquer ciência, a materialidade do real não se reduz às construções linguísticas, topológicas, lógicas e matemáticas. A estrutura do inconsciente e o circuito da pulsão indicam que as dimensões do simbólico e do imaginário não vagueiam ao sabor do nominalismo, mas convergem em direção a um referente real. Este último, por melhor formalizado que seja, escapa ao sentido. Por esta razão, no último ensino de Lacan o real não é mais determinado pelo simbólico. Não é um resíduo. Real e simbólico são pensados como radicalmente disjuntos. A única infração à regra de que não há sentido no real é o sintoma, pois ele é uma conjunção entre o real e o sentido. Enquanto uma prática com raízes no campo da medicina, existe na psicanálise também alguma coisa que não se ensina: a arte de ler e interpretar o sintoma. Não se ensina, mas se pode transmitir por meio de nossa prática, e é por esta razão que não existe nenhum analista que não seja a consequência boa ou ruim de sua própria análise. É na prática dos analistas que devemos buscar evidências de um pathos revolucionário na relação ao real.

Minha hipótese (Coelho dos Santos \& Lopes, 2013) é a de que a psicanálise participa de duas concepções do real, cujo fundamento, entretanto, é único: o real é impossível. O saber que extraímos de nossa prática pode ser formalizado. Haverá sempre, em cada experiência analítica, o encontro com uma singularidade irredutível, um corpo do qual se usufrui. Em que medida o espírito, o gosto e o apelo revolucionário podem ser classificados em conformidade com a relação que manifestam ao real enquanto impossível? Qual é o lugar que o conceito de revolução pode ocupar no nosso campo? A pulsão de morte, o real, o trauma, a angústia, a violência, a feminilidade, por exemplo, são conceitos que apontam para uma disposição potencialmente revolucionária que habitaria a esfera mais íntima de cada um? Haveria um pathos revolucionário, que algum destes 
conceitos permite abordar? A travessia do fantasma, a reiteração do sinthoma como resto de uma análise testemunhariam o pathos revolucionário do processo analítico?

Antes de recolher indícios do posicionamento de Freud ou de Lacan sobre este tema, fui compelida a me situar relativamente a esta outra questão: o que é que define um pensamento e uma ação política de direita ou de esquerda? ${ }^{4}$. Parto da premissa de que a referência central que as distingue é o conceito de revolução.

\section{Sobre o conceito de direita e esquerda}

Roger Scruton (2014) se pergunta "What's left?", jogando com o duplo sentido. "O que é esquerda?", mas, também, "O que se deixa?". Ou ainda, "O que sobra?". Sua obra destina-se a questionar o prestígio excessivo alcançado por alguns intelectuais da "New Left" (Nova Esquerda) e a influência, talvez, abusiva que exerceram sobre todo o campo do pensamento nas ciências humanas. Em outro artigo recente (Coelho dos Santos, 2016, mai. a out.) já tratei deste assunto, recuperando alguns questionamentos desta mesma tradição filosófica, a da Nova Esquerda, veiculados numa obra crítica de Luc Ferry e Alain Renault intitulada Pensamento 68. Na ocasião, pude interrogar o gosto histérico pelas rebeliões, revoluções e revoltas que caracterizam o período que sucede aos acontecimentos de maio de 1968. Meu interesse, naquele momento, era o de situar a afinidade ou a ruptura do pensamento psicanalítico de Freud e Lacan com os ideais de 1968. Neste artigo pretendo ir um pouco mais longe, reformulando a minha questão da seguinte maneira: a psicanálise pode ser situada à esquerda ou à direita? E se minha premissa é correta, que lugar a referência revolucionária tem no pensamento freudo-lacaniano?

Raymond Aron (2016) já se interrogava nos idos de 1955 se a alternativa entre direita e esquerda tinha ainda algum significado. Para mostrar que estava bem advertido da repercussão negativa de sua pergunta, recordava a sagaz observação de Alain (1934, apud Aron, 2016) ${ }^{5}$ acerca de quem são os que questionam se esta divisão faz sentido. Certamente não são de esquerda, dizia ele. Logo, a esquerda acredita mais nessa divisão do que a direita. Aron questiona a insistência em manter a oposição entre estes dois termos, que não seriam apenas dois blocos políticos, mas também a suposta existência de dois modelos de homem com atitudes fundamentalmente contrárias. Ou, ainda, duas concepções distintas em um diálogo que prossegue, sempre o mesmo, apesar das mudanças de vocabulário e instituições. E discorda vivamente que estes dois tipos de homens, de filosofias e de partidos, existam fora da imaginação de historiadores.

Aron (2016) não coloca no centro da discussão a referência da esquerda à revolução, mas ao analisar os mitos principais dos intelectuais de esquerda, situa claramente a crença no mito da revolução entre os principais. A França teria sido supostamente a pátria do antagonismo entre direita e esquerda. Este antagonismo tem origem na oposição sangrenta entre a concepção de mundo inspirada em preceitos católicos do Antigo Regime e a nova mentalidade que preparou a explosão revolucionária, voltando-se contra o princípio de autoridade tanto da Igreja, quanto da monarquia. 
No final do século XVIII e ao longo da maior parte do século XIX o combate ao "trono" e ao "altar" marcou a passagem do Antigo Regime para a sociedade moderna com uma brusquidão e brutalidade sem par. Diferentemente da França, o regime constitucional e as instituições representativas no parlamento foram progressivamente instalados na Inglaterra, apoiados nos costumes medievais. A legitimidade democrática substituiu a monárquica, apagando pouco a pouco a distinção entre a plebe e a nobreza. A Revolução Francesa, diferentemente, lançou suas ideias de soberania do povo, de exercício da autoridade dentro de regras, de assembleia eleita e soberana e de supressão das diferenças de status individual como um vendaval através da Europa. Na Inglaterra, elas se realizaram sem que o povo fosse levado a libertar-se de seus grilhões pela violência. Vale ressaltar que a catástrofe ou a epopeia revolucionária dividiu a França em duas. Cada uma encarna um tipo humano quase eterno. De um lado, evoca-se a família, a autoridade, a religião. De outro, ressalta-se o valor da igualdade, da razão, da liberdade. Em uma se respeita a ordem que séculos e séculos lentamente elaboraram. Em outra, se promove a capacidade do homem de construir seu destino com o apoio na ciência: "A direita, partido da tradição e dos privilégios, contra a esquerda, partido do futuro e da inteligência" (Aron, 2016, p. 17).

Como não se trata aqui de fazer juízos históricos acerca de preferências políticas, mas de situar a posição do pensamento freudo-lacaniano sobre o tema, concluo que a divisão entre direita e esquerda interessa aos revolucionários. Os partidários da conservação da tradição preferem que as mudanças sejam assimiladas sem rupturas bruscas e sangrentas. A meu ver, independentemente das graves questões sociais, políticas e econômicas envolvidas nessa transição de uma época à outra, subsiste uma questão eminentemente pulsional que diz respeito ao "gosto". Freudianamente, remete talvez à misteriosa escolha da neurose (Neurosenwah). O gosto revolucionário, a inclinação à rebeldia, pode fundar-se na interpretação da castração como abuso de poder ou privação de um direito? De Lacan (1959-1960/1998) eu retomaria a tese sobre a pulsão de morte: vontade de destruição direta e de recomeço com novos custos. Recordo também sua observação acerca de um novo gosto, uma felicidade no mal, que floresce no rastro do iluminismo. A tese de Lacan (1966/1998) é ousada. A obra de Sade é acadêmica, nela se prepara a ciência, retificando a posição da ética aristotélica fundada na dominância do princípio do prazer. Este princípio repousa sobre a suposta universalidade da lei do bem-estar. A filosofia da alcova de Sade surge oito anos depois da Crítica da razão prática, de Kant. Mais além do princípio do prazer que é a lei do bem-estar (WohI), Kant introduz um outro bem (Gute), o objeto da lei moral, que nos permite entender porque ficamos bem no mal. Experimentamos este outro bem (Gute) por meio da experiência que temos de ouvir dentro de nós ordens cujo imperativo se apresenta como categórico ou incondicional. É através da dimensão do supereu, experiência intrasubjetiva da lei moral, que penso poder introduzir o tema do gosto revolucionário em oposição ao gosto conservador. Para tanto, vale recordar que a separação insuperável entre o simbólico-imaginário e o real pode ensejar as passagens ao ato, o impulso à transgressão, o suicídio ou o assassinato. As tragédias bem evidenciam esse ponto. A posição 
subjetiva diante do real, que impele alguns à passagem ao ato, pode conduzir outros tantos a esgueirarem-se. 0 pathos revolucionário pode ser classificado como uma escolha pela passagem ao ato?

De acordo com Scruton (2014), nos anos 1960-1970, uma "Nova Esquerda" ergueu um promontório hostil e instransponível para formar um consenso de oposição. Sob a influência desse consenso, não é mais respeitável defender os costumes, as instituições e a política dos Estados ocidentais, e muitos intelectuais voltaram a aceitar a teoria e a prática do comunismo. Não se trataria, ainda segundo o mesmo autor, de uma divergência inadvertida, mas da mais recente explosão de uma força proeminente na política desde 1879. O intelectual de esquerda seria tipicamente um jacobino. Acredita que o mundo é deficiente em sabedoria e justiça e que a falha reside nos sistemas de poder estabelecidos e não na natureza humana. É um defensor da justiça social em proveito dos oprimidos. É também um libertário. Revolta-se contra a opressão interna e externa que rege o mundo. Acredita que a humanidade está atada a cadeias de exploração e a uma escravidão interna que deforma e mutila a alma. $\mathrm{O}$ autor faz uma crítica à pretensão dos intelectuais de colocarem-se acima ou do lado de fora das amarras dos interesses estabelecidos pelos supostos sistemas de poder. A política de esquerda regozija-se com o ardor do combate em defesa da justiça social. O lugar do político de esquerda é julgado pelo limite até onde ele está disposto a ir em defesa dos "objetivos", entenda-se, revolucionários.

A política conservadora, diferentemente, na tradição inglesa é uma política do costume, compromisso e firme indecisão. A associação política deve ser avaliada do mesmo modo que a amizade, ela não tem um propósito, muda permanentemente de acordo com a imprevisível lógica do curso das coisas entre os homens. Extremistas conservadores são considerados indivíduos isolados, excêntricos ou até perigosos. Os movimentos de esquerda, ao contrário, são frequentemente liderados por fanáticos:

Em 1794, Robespierre prometeu "estabelecer na terra o império da sabedoria, justiça, virtude" e seus sucessores rivalizaram com ele na pompa e no anticlímax de suas reivindicações. Rosa Luxemburgo disse aos seus inimigos que "amanhã a revolução ascenderá ecoando a toda altura e, para sua consternação, anunciará ao som de todas as trombetas: eu era, eu sou, eu serei"; seu camarada Karl Liebnecht prosseguiu: "Estamos lutando pelos portões do paraíso". (Scruton, 2014, p. 16)

\section{Sobre o conceito de revolução e seu pathos}

Antes de enveredarmos no tema da subjetividade de direita ou conservadora, vamos aprofundar um pouco mais a relação entre a política de esquerda e a perspectiva revolucionária. Como definir o conceito de revolução? Arendt (2016) afirma que por mais que seja necessário 
distinguir na teoria e na prática entre guerra e revolução, a relação de ambas com a violência é suficiente para distingui-las de outros fenômenos políticos: "Seria difícil negar que uma das razões pelas quais as guerras se convertem tão facilmente em revoluções e as revoluções têm mostrado essa sinistra tendência de desencadear guerras é que a violência constitui uma espécie de denominador comum a ambas" (Arendt, 2016, p. 44).

O pathos revolucionário poderia ser definido como "vontade de destruição direta, de recomeço com novos custos", tal como Lacan define a pulsão de morte? Que posição subjetiva diante do real impele à revolução? A mesma que incita à passagem ao ato, à transgressão, ao suicídio ou ao assassinato? É esta a posição que prevalece ao final de uma análise? Como a violência é a protagonista das guerras e das revoluções, estas se desenrolam fora da esfera política. A hipótese de um estado de natureza, que atravessa todo o pensamento jusnaturalista, manifesta a crença num estado da sociedade pré-político, ao mesmo tempo em que acredita que é por meio da violência que se chega ao estado de uma sociedade política: "A narrativa foi clara: qualquer fraternidade de que sejam capazes os seres humanos nasceu do fratricídio, qualquer organização política a que tenha chegados os homens teve origem no crime" (Arendt, 2016, p. 46).

A convicção de que no início houve um crime - metáfora que encontramos também na obra freudiana, "Totem e Tabu", acerca do assassinato do pai primordial - tem relação com as revoluções modernas, pois são eventos políticos que pretendem fundar um novo início pela violência original. Defendi a tese de que "Totem e Tabu" é uma obra que aborda a passagem do estado pré-político ao estado político (Coelho dos Santos, 2001). Freud remete essa mutação à fundação da própria civilização. Não se trata da passagem da natureza a cultura, pois a origem parece perdida desde sempre, e sim da passagem da horda humana à organização social. Arendt (2016), diferentemente, distingue as revoluções modernas das mutatio rerum da história romana ou da guerra civil que afetava a polis grega. Não se trata mais, no caso das revoluções modernas, de uma transmutação de uma forma de governo para outra, nem do ciclo que rege os assuntos humanos. Embora a violência estivesse presente nas mudanças políticas gregas, estas últimas não interrompiam o curso do que chamamos modernamente de história. Eram um estágio de um ciclo e não inauguravam um novo início. Tal como nas revoluções modernas, a motivação econômica constituía-se ordinariamente na força motriz das lutas políticas pela igualdade de condições. Aristóteles teria sido o primeiro a afirmar que o interesse (o que é útil para alguém, um grupo ou um povo) é e deve ser a norma suprema a reger os assuntos políticos. Posição oposta à de Kant em $A$ crítica da razão prática, que opõe ao interesse o soberano Bem, fundando na relação a este último, a ação virtuosa. Diferentemente das revoluções modernas, a distinção entre pobres e ricos era considerada natural e não era isso que justificava o uso da violência. Somente na era moderna, e não antes, a pobreza deixa de ser considerada como inerente à condição humana e a desigualdade entre ricos e pobres um dado essencial. Arendt traz uma citação de John Adams - mais de uma década antes de eclodir a Revolução Americana - bastante convincente sobre esta mudança de percepção da pobreza: 
"Sempre considero a colonização da América como a inauguração de um grandioso plano da Providência para o esclarecimento dos ignorantes e a emancipação da parcela escrava da humanidade em toda a Terra"6 (Adams, 1765/1850-1856, apud Arendt, 2016, p. 49).

Estas condições sociais inéditas proporcionaram um asilo para os pobres e alimentaram 0 impulso revolucionário na Europa. No Velho Mundo, entretanto, a igualdade, que se desenvolvera de maneira natural no Novo Mundo, só pode ser alcançada por meio da violência e da carnificina. Frequentemente se atribui à doutrina cristã a origem de todas as revoluções modernas. A natureza rebelde da seita cristã primitiva e a ênfase na igualdade das almas diante de Deus, seu desprezo pelos poderes públicos e a promessa de um Reino celestial justificam essa atribuição. Para os propósitos deste trabalho, a hipótese de Arendt merece ser examinada com atenção, pois parece repercutir a tese lacaniana acerca da pulsão de morte. As revoluções, poderíamos dizer, fazem parte de um novo gosto, uma espécie de felicidade no mal: vontade de destruição direta e de recomeço com novos custos. A autora ressalta justamente o elemento de novidade inerente a todas as revoluções modernas. O conceito moderno de revolução está ligado à ideia de que o curso da história se inicia de novo, após uma ruptura inaugural, desencadeando uma história jamais narrada ou conhecida até então.

Razão pela qual Condorcet ${ }^{7}$ teria afirmado que somente podem ser consideradas revolucionárias as revoluções cujo objetivo é a liberdade. A simples rebeldia pela libertação de condições materiais opressivas não é suficiente para caracterizar a novidade que se define pela convergência entre a ideia de liberdade e a experiência de um novo início. Libertação e liberdade não são conceitos equivalentes. A intenção de libertar-se não é a mesma coisa que o desejo de liberdade. $O$ conceito de liberdade política que nasce com as revoluções modernas não se resume à expansão do acesso a direitos civis: a vida, a liberdade e a propriedade. É a experiência da capacidade do ser humano de dar início a algo novo. Está na raiz das revoluções francesa e americana, com toda a insistência reiterada de que nunca acontecera nada comparável em grandiosidade e importância na história da humanidade, o pathos da novidade. Não se deve confundi-lo com o entusiasmo das insurreições bem-sucedidas. Nas revoluções modernas não se trata de um golpe em que o poder muda das mãos de um grupo para outro. Também não é somente a violência que pode ocorrer tanto num caso, quanto noutro o que especifica a revolução.

Mas a violência tal como a mudança, não é adequada para descrever o fenômeno da revolução; apenas quando a mudança ocorre no sentido de criar um novo início, quando a violência é empregada para constituir uma forma de governo totalmente diferente e para gerar a formação de um novo corpo político, quando a libertação da opressão visa pelo menos a constituição da liberdade, é que se pode falar de revolução. (Arendt, 2016, p. 64) 
Não é difícil concordar com Arendt acerca do entusiasmo ou do gosto pela novidade que se pode verificar nas narrativas sobre as revoluções modernas, se as comparamos às insurreições, revoltas, golpes e outros processos mais ou menos violentos de mudança política. A diferença é muito fácil de situar ao nível das doutrinas revolucionárias. É mais fácil ainda de situar se a referimos à fundação do Estado moderno laico, separado da Igreja. A declaração dos direitos do homem, a afirmação de que todos nascem livre e iguais, desconstrói a estrutura piramidal e hierárquica que sustentou o regime feudal de castas. Em sua análise, ela parece querer fundar em razão, o surgimento de um espírito revolucionário inédito sem que seja preciso situá-lo no plano das doutrinas filosóficas que orientaram as transformações históricas que se seguiram aos eventos revolucionários. A ênfase da emergência de algo novo no terreno do espírito humano, que seria preciso datar, pode verificar-se na citação que se segue:

Uma maneira de datar o nascimento efetivo de fenômenos históricos gerais como revoluções - ou, a propósito, os Estados nacionais, o imperialismo, o regime totalitário e outros - é, naturalmente, descobrir a primeira vez que aparece a palavra e, a partir daí, passar a vincular ao fenômeno. É óbvio que todo novo aparecimento entre os homens requer uma palavra, quer se cunhe um termo para designar a nova experiência, quer se utilize um termo antigo com significado totalmente novo, isso se aplica duplamente à esfera política da vida, onde a fala reina suprema. Portanto, não é um simples interesse antiquarista observar que a palavra "revolução" ainda está ausente daquele lugar em que mais tenderíamos a pensar que se faria presente, a saber, a historiografia e a teoria política do começo do Renascimento na Itália. (Arendt, 2016, pp. 64-65)

A palavra revolução foi usada originalmente no campo da astronomia e ganhou prestígio científico graças a Copérnico. Em latim, designava o movimento regular e necessário dos astros em suas órbitas, num movimento cíclico e recorrente, irresistivelmente fora do alcance dos seres humanos. Para designar pela primeira vez os acontecimentos políticos, seu uso era uma metáfora de um movimento eterno, irresistível, recorrente aplicada aos movimentos imprevistos do destino humano. Tal como a sucessão do dia e da noite, as fases da lua e das estrelas, tratava-se de designar um movimento de retorno a algum ponto preestabelecido, a uma ordem predeterminada. Em outro artigo, mencionei a posição reticente de Lacan acerca do gosto revolucionário:

Uma vontade tão exacerbada de revolução pode indicar um desejo de encontrar um mestre muito mais forte. Freud (1921/1976) se refere ao fenômeno hipnótico que parece dominar as relações entre as massas e certos líderes. E Lacan (1969-1970/1991, p. 52), argumenta que ímpetos revolucionários conduzem ao 
ponto de partida, isto é, o reforço da função da mestria. Grande parte dos indivíduos rebeldes sonham, talvez, com um grande Outro muito mais poderoso. Lacan adverte que não se pode confundir a verdade analítica com a revolução. (Coelho dos Santos, 2016, p. 8)

Voltemos ao tema do surgimento da palavra revolução. Não foi quando Cromwell instaurou a Revolução Inglesa que a palavra foi usada pela primeira vez no campo político, e sim em 1660, depois da derrubada do Parlamento residual e com a restauração da monarquia. Em 1688, o termo Revolução Gloriosa designava a restauração do poder monárquico à sua virtude e glória anteriores. O exame da Revolução Francesa e da Revolução Americana também testemunha que a ambição dos homens que as empreenderam era a de restaurar uma antiga ordem de coisas que fora perturbada e violada pelo despotismo da monarquia absoluta ou pelos abusos do poder colonial. Arendt reconhece que:

É impossível dizer se tais homens eram 'conservadores' ou 'revolucionários, se usarmos tais palavras fora do contexto histórico, como termos genéricos, esquecendo que o conservadorismo como ideologia e crença política deve sua existência a uma reação à Revolução Francesa e só faz sentido para a história dos séculos XIX e XX. (Arendt, 2016, p. 75)

Arendt (2016) reconhece, apesar de tudo o que defendeu anteriormente, que Maquiavel é quase um precursor no que se refere a uma história da ideia de revolução. Suas reflexões acerca da teoria política não se prendiam à resposta tradicional, segundo a qual o governo de um só leva à democracia, a democracia leva à oligarquia, a oligarquia leva à monarquia e inversamente. Seu interesse, em que pese o inventário de incontáveis mutações, alterações e variações, seria pelo imutável, o permanente e o duradouro. Foi o primeiro a pensar na possibilidade de fundar um corpo político permanente, constante, duradouro. Também foi o primeiro a visualizar o surgimento de um âmbito secular, cujas leis e princípios de ação seriam independentes das doutrinas da Igreja. Insistia que o homem que ingressava na política deveria aprender a "não ser bom", a não agir segundo os princípios cristãos. Embora desejasse uma renovação da Itália, a criação de um Estado nacional, segundo Arendt, não ensejaria, em Maquiavel, o pathos revolucionário, o gosto pelo absolutamente novo. Opinião que diverge, como ela mesma destaca, de Robespierre, para quem o plano da Revolução Francesa teria sido totalmente escrito nos livros de Maquiavel. Em particular, pode ser considerado o pai espiritual da revolução, por sua insistência no papel da violência no âmbito da política, a despeito de sua admiração explícita pela república romana, onde a autoridade, e não a violência, regia a conduta dos cidadãos. 
Se $o$ ato de fundação de um novo início requer a violação, a violência, a tarefa de legislar, de criar e impor aos homens uma nova autoridade que conseguisse ocupar o lugar da antiga autoridade absoluta, é porque requer o que Freud (1913/1974) nomeou como a dívida paterna, o restabelecimento do "amor". Tema que se encontra ausente do pensamento de Maquiavel e de Arendt, em consequência da opção antirreligiosa. Maquiavel não teria encontrado alguma qualidade em certos homens comparável às qualidades que associamos ao divino. Freud, em seu mito "Totem e Tabu", diferentemente, vai buscar nos sentimentos de remorso, culpabilidade, dívida e amor, a saída para o impasse de fundar uma nova autoridade que substitua a do pai primordial assassinado. Esta é uma diferença essencial entre seu pensamento e o daqueles que, alicerçados exclusivamente na ciência, não reconhecem que sem a sobrevivência da religião, da crença inconsciente no pai, é impossível fundar o exercício da autoridade na modernidade.

Arendt (2016) empreende um esforço memorável para convencer seus leitores de que o estranho pathos da novidade, tão típico da era moderna, precisou de duzentos anos para sair do relativo isolamento da área científica e filosófica e chegar ao campo da política. Neste campo, a invenção de uma nova forma de felicidade, a felicidade pública de acordo com os americanos, acompanha o nascimento de um novo gosto, a paixão pela liberdade pública, na linguagem dos franceses. Esta deve ser entendida de acordo com a formulação de Montesquieu e de Burke como interesse apaixonado pela liberdade pública. Reunidos em assembleias e convenções, os homens exerciam o novo gosto pela discussão, pela deliberação, pela tomada de decisões com paixão pela virtude da distinção, da emulação e do desejo de ser melhor que o outro. O novo gosto engendrava também um novo vício, a ambição que visa o poder pela distinção. Diferentemente do tirano que não tem nenhum desejo de sobressair, nem qualquer paixão pela distinção, os homens da revolução apreciam na companhia de seus pares na esfera dos assuntos públicos. Esta liberdade ou felicidade não deve ser confundida com o bem-estar privado. Existe uma diferença, nas palavras de Tocqueville (1953, apud Arendt, 2016) entre aqueles que "parecem amar a liberdade e apenas odeiam seus senhores" e aqueles que sabem que "quem procura na liberdade outra coisa além dela mesma é feito para servir"

\section{A revolução como um mito da esquerda}

Para Raymond Aron (2016), o conceito de revolução não desperta nenhum entusiasmo e não encanta pela novidade. O mito da esquerda contém a ideia de progresso e de movimento contínuo. O mito da revolução tem um significado complementar e oposto, alimentando a expectativa de ruptura com o ritmo ordinário das coisas humanas. Audaciosos na teoria, aqueles que a posteriori parecem ter preparado a Grande Revolução, não anunciavam nem desejavam derrubar o velho mundo. A maior parte era otimista, acreditava que afastados os preconceitos, as tradições, o fanatismo, uma vez que os homens fossem esclarecidos, a ordem natural das sociedades seria alcançada. A partir de 1791 ou 1792, a Revolução foi percebida pelos seus contemporâneos como 
uma catástrofe. Muitos fiéis ao espírito da revolução se esforçaram para esquecer o terror, o despotismo, o ciclo de guerras e todas as peripécias sangrentas. Outros, ao contrário, enfatizaram a tomada do poder e a subversão. Acreditavam na violência como a única força capaz de fabricar o futuro. Desconfiado, o autor se pergunta se as revoluções merecem ser tão valorizadas.

Sobre o conceito, propõe que: "Entende-se por revolução, na linguagem corrente da sociologia, a substituição brusca, pela violência de um poder por outro" (Aron, 2016, p. 48). Não é difícil perceber que esta definição, diferentemente da que foi desenvolvida por Arendt por meio da ideia de pathos da novidade, é negativa. A rigor, Aron não acredita que exista uma essência eterna da revolução, logo, não existe, talvez, nenhum pathos específico, somente uma opção pela esquerda:

Na verdade, quando se fala de revolução, quando nos perguntamos se determinada ascensão brusca e violenta ao poder é digna ou não de entrar no templo em que se encontram 1789, os "três gloriosos" dias de julho de 1848 e "os dez dias que abalaram o mundo", referimo-nos mais ou menos conscientemente a duas ideias: as revoluções, tais como as observamos em diversos países sangrentas, prosaicas, decepcionantes -, só se filiam à Revolução com a condição de terem uma ideologia de esquerda, humanitária, liberal, igualitária. Só se cumprem plenamente se conseguirem a derrubada das relações atuais de propriedade. No plano da história, essas duas ideias são simples preconceitos. (Aron, 2016, pp. 5051)

Para Aron, um poder revolucionário é necessariamente tirânico, pois ignora as leis, exprime a vontade de um grupo mais ou menos numeroso, toma o poder pela violência quando existem conflitos não resolvidos pela negociação e o compromisso, coroando o fracasso dos procedimentos democráticos. Logo, democracia e revolução são noções contraditórias. Entretanto, a Grande Revolução faz parte da herança nacional da França. Os franceses adoram a palavra "revolução", pois parece evocar e prolongar a grandeza passada:

Apaixonado por ideias e indiferente às instituições, crítico implacável da vida privada mas rebelde, em política, às considerações da razão, o francês é basicamente revolucionário em palavras e conservador em atos. O mito da revolução, porém, não se limita aos franceses. Ganhou prestígios diversos, em geral mais forjados do que autênticos. (Aron, 2016, p. 55)

Aron questiona vivamente a ideia que subjaz o imperativo revolucionário: "A revolução, argumenta, não se confunde com a ação, não sendo mais do que uma das suas modalidades" (Aron, 2016, p. 58). O mito revolucionário coloca a violência a serviço da razão, mas a revolução não é 
fatalidade, nem vocação, apenas um meio dentre outros para um fim. No marxismo, argumenta, se encontrariam três concepções divergentes de revolução. Uma concepção herdada de Auguste Blanqui, socialista francês do século XIX, de tomada de poder por um grupo armado que transforma as instituições depois de conseguir tomar o Estado. Uma concepção evolutiva, em que a sociedade futura deve amadurecer dentro da sociedade atual antes do desenlace final. E a terceira, da revolução permanente, com o partido operário exercendo uma pressão constante até a queda da ordem capitalista e o advento do socialismo. Logo, se há um pathos que beneficia a revolução é o prestígio da revolta, o ódio contra a ordem ou a desordem estabelecida:

Metafísica, a revolta nega a existência de Deus e os fundamentos que a religião ou o espiritualismo tradicionalmente garantiam aos valores ou à moral. Ela denuncia o absurdo do mundo e da vida. Histórica, a revolta acusa a sociedade como tal ou a sociedade presente. Muitas vezes, uma leva à outra, mas nenhuma leva inevitavelmente à revolução ou aos valores que a causa revolucionária pretende encarnar. (Aron, 2016, p. 60)

Quem são os revoltados? São aqueles que fazem oposição à ordem estabelecida, pois veem nas proibições e imperativos sociais somente convencionalismo e hipocrisia. Nem todos se revoltam contra Deus. Bernanos e Nietzsche, o primeiro acreditando em Deus e o segundo proclamando sua morte, são não conformistas, recusam tanto a democracia, quanto o socialismo e o regime das massas. São hostis, ou pelo menos indiferentes à elevação do nível de vida, à generalização da pequena burguesia, ao progresso da técnica:

Revoltados ou niilistas criticam o mundo moderno, uns por ele ser o que quer ser, outros por ele não ser fiel a si mesmo. Os últimos são mais numerosos, hoje em dia, do que os primeiros. As polêmicas mais vigorosas se armam não entre uns e outros, mas entre intelectuais que estão de acordo sobre o essencial. Para que se dilacerem, nem precisam se opor com relação à finalidade, basta divergir quanto à palavra sagrada: revolução. (Aron, 2016, p. 62)

Analisando as diferenças entre dois escritores como Albert Camus e Jean-Paul Sartre, Aron questiona a suposição de que as diferenças entre eles justifiquem uma ruptura. São dois humanitários, desejam atenuar os sofrimentos, libertar os oprimidos, combater o colonialismo, o fascismo e o capitalismo. $O$ que os separa é a atitude com respeito à União Soviética e ao comunismo. Camus considera o projeto revolucionário a mais completa tirania, pois nega qualquer valor eterno, toda moral transcendente à luta de classes e à diversidade de épocas. Sobretudo, acusa-os de 
sacrificar homens vivos por um bem pretensamente absoluto, o fim da história. Sartre, embora não negue as acusações de Camus, se recusa a romper com o projeto revolucionário.

Aron conclui sua análise caracterizando, finamente, o pathos em jogo nas revoluções por meio do caso francês. Observa que os intelectuais franceses falam sem parar de revolução - cristã, socialista, gaullista, comunista, existencialista - convencidos de que os grandes cataclismos são iminentes. As revoluções nasceriam muito mais do desespero ou da esperança do que da insatisfação. Sociedade paralisada e inteligência ideológica não são fenômenos contraditórios: na verdade, formam um sistema. Quanto menos a inteligência adere ao real, mais devaneia com revoluções. Quanto mais a realidade parece cristalizada, mais a inteligência identifica a sua missão como crítica ou recusa. Incapazes de quererem um futuro em comum, os franceses não têm a esperança que impele as multidões. Nunca tiveram a sabedoria de dispensar os ideais. As tarefas a serem cumpridas não os empolgam se ideologia nenhuma as transfigurar. As ideologias os colocam uns contra os outros, mas temperam as paixões contraditórias com ceticismo. E o ceticismo não é revolucionário. É preciso uma dose de otimismo e impaciência. Há revolucionários por ódio ou por aspiração à catástrofe, mas, em geral, são otimistas. Todos os regimes são imperfeitos e condenáveis se comparados ao ideal abstrato de igualdade e liberdade. Somente a revolução, por ser uma aventura, ou um regime revolucionário, por consentir no uso permanente da violência, seria sublime. A violência atrai e fascina mais do que causa aversão. O mito da revolução serve de abrigo para o pensamento utópico, tornando-se o misterioso intercessor entre o real e o ideal.

\section{Observações sobre o conceito e o pathos conservador}

Retorno ao ponto de partida. Roger Scruton intitula o capítulo final de seu livro por meio da pergunta equívoca: "What is right?", que pode significar tanto "o que é a direita?", quanto "o que é certo?". Diferentemente do homem de esquerda, a direita não vê igualdade e liberdade como profundamente compatíveis e realizáveis por meio da destruição do poder. A condição da sociedade é a dominação, que vincula as pessoas umas às outras por emoções e lealdades, e as separa por rivalidades e poderes. Não há sociedade que possa abrir mão destas realidades humanas e é destes componentes que nossas satisfações mundanas são compostas. Onde há lealdade, há poder. Onde há rivalidade, há necessidade de governo. Por esta razão, a preocupação dos seres políticos à direita não é a de abolir os poderes que unem a sociedade, mas garantir que eles não sejam usados para dividi-la. O exercício pacífico do poder, a resolução dos conflitos por meio da justiça natural que habita silenciosamente o intercurso social humano, sem a saída pelo radicalismo e pelo projeto revolucionário: "O americano liberal está tão convencido do mal da dominação quanto está o parisiense guauchiste. Ele só se distingue por reconhecer que as instituições são, no fim, necessárias para o seu propósito, e que a ideologia não é um substituto para o trabalho paciente da lei" (Scruton, 2014, p. 289). 
Crítico dos revolucionários, o homem à direita acredita que o "sistema" é consensual, mas a sociedade que o radical de esquerda deseja não o é. A liberdade humana verdadeira seria limitada pela circunstância humana, e então, não pode ser libertada do "verme da dominação". A esquerda confundiria poder com coerção. O poder é visto como odioso e a sociedade dividida em classes. Os indivíduos são percebidos como idênticos à classe à qual pertencem. Assim, os proprietários dos meios de produção - os empregadores - são necessariamente exploradores do trabalho alheio:

Se as classes são agentes, então é possível dizer que burguesia enquanto classe coage o proletariado em outras palavras, a falta de poder do proletariado é também uma falta de liberdade. Mais agora é possível culpar a burguesia como uma classe e, e cada membro dela individualmente, pelos sofrimentos dos despossuídos. (Scruton, 2014, p. 296)

Com toda certeza, Foucault concordaria com Scruton sobre a necessidade de distinguir o poder da coerção externa, mas ele não sabe disso. Acredita que é um crítico de toda a "Nova Esquerda", mas não leu ou não compreendeu corretamente nem Foucault, nem Althusser. Sobre a correlação entre o conceito de poder e o conceito freudiano de pulsão, já escrevi (Coelho dos Santos, 2001) há muito tempo. O que os aproxima é a certeza de que não existe laço social isento de relações de poder. O esforço de Foucault é o de dissociar a noção de poder das noções de classe dominante, de Estado ou de aparelhos do Estado. Freud, por sua vez, mostrou que o poder não se reduz à autoridade paterna, pois a pulsão é uma força constante (Konstant Kraft), que pressiona (Drang) para atingir seu objetivo (Zie). É o representante psíquico das excitações com origem no corpo. Lacan, por sua vez, articulou o nascimento da pulsão aos efeitos da linguagem sobre o corpo. A pulsão resulta do encontro traumático entre corpo e linguagem. Nada mais distante de uma ideia do poder como repressão ou coerção externa. O poder é o poder concreto que cada um exerce como agente, para Freud, Lacan, Foucault ou Scruton. Foucault não dissolve o indivíduo na classe social, ao contrário do que pensa Scruton. Mas, Scruton acredita muito mais que no Estado de Direito e em suas instituições. Acredita muito mais que o exercício da democracia depende do aperfeiçoamento das instituições. Foucault, me parece, aposta muito mais nas ações e movimentos sociais. Neste sentido, a despeito de sua concepção pervasiva do poder, percebe-se nele um resto de gosto revolucionário.

A Nova Direita (se eu puder apropriar-me do rótulo) acredita mais em governo responsável do que em governo impessoal; na autonomia e personalidade das instituições e no Estado de Direito. Ela reconhece uma distinção entre Estado e sociedade civil, e acredita que o segundo deve advir, em geral, da interação livre de indivíduos contratantes, mediados pelos costumes, a tradição e o respeito pela 
autoridade e pela lei. Poder, para a Nova Direita, é um mal somente quando abusado. Pois o poder surge naturalmente da interação humana, e é meramente a consequência irrepreensível de um acordo cujas virtudes estão por toda a parte. (Scruton, 2014, p. 302)

A concepção foucaultiana de poder não é a mesma, embora comungue esta propriedade de ser inerente ao laço social. O ponto de divergência é a oposição à teoria do contrato social e às concepções jurídicas do poder. Como Scruton, Foucault não reduz o poder à interdição da lei. Considera que a criação do Estado é somente a forma terminal do poder. Não está distante do que pensa Scruton neste ponto também. E acredito que este último estaria parcialmente de acordo com a definição foucaultiana do poder. Não é algo que se adquira, se arrebata ou ceda... O poder se exerce: "que lhe seja dado como modelo antes a batalha perpétua que o contrato que o contrato que faz uma cessão ou a conquista que se apodera de um domínio" (Foucault, 1977, p. 29).

Pois, diferentemente de Foucault, Scruton não rejeita a ordem jurídica e a ficção contratual que organiza as sociedades ocidentais. Ele os encara como semblantes que asseguram os instrumentos que nos permitem negociar acordos, assumir compromissos e, sobretudo, manter uma versão humanizada do Estado. O Estado de Direito, como o conhecemos, não é uma coisa, é uma pessoa:

Como toda pessoa, o Estado é responsável perante outras pessoas: o sujeito individual, as corporações e outros Estados. É também responsável perante a lei. Tem direitos contra o indivíduo e deveres em relação a ele; é tutor, companheiro da sociedade, alvo de suas piadas e o recipiente da raiva. Ele estabelece conosco uma relação humana, e esta relação está sustentada e justificada pela lei, diante da qual ele se porta como uma pessoa como as outras, em pé de igualdade com seus sujeitos. (Scruton, 2014, pp. 310-311)

Poderíamos, a esta altura, iniciar uma discussão acerca do lugar da teoria freudiana do Édipo nas concepções políticas de esquerda e de direita. Pode-se dizer que a direita não concebe o avanço, o progresso, a transformação dos laços sociais como devendo passar pela morte de Deus ou pela morte do pai. A esquerda, diferentemente, aposta em prescindir do pai, destroná-lo, destrui-lo e erguer laços novos socialistas e igualitários. A direita não acredita em igualdade socialista entre os homens. O pressuposto da diferença, da hierarquia, da desigualdade natural é o combustível que alimenta as trocas sociais e as ambições. Para a direita o indivíduo é um valor. Para a esquerda é um vício a ser reduzido em proveito do coletivo. A liberdade não é um tema de que se ocupam os psicanalistas. Em primeiro lugar, porque não acreditam (quando são psicanalistas de verdade) que todo homem nasce livre e igual. O homem nasce pequeno, desamparado e dependente do outro 
que o deseja ou não. É sintoma de um homem e de uma mulher, e padece das marcas dessa relação primordial ao desejo de seus pais para constituir-se como um corpo pulsional. Não é livre nem em relação ao que lhe é inconsciente, nem em relação às fixações de gozo pulsional que orientam sua busca, seja no campo do desejo, seja no campo da satisfação. A esquerda revolucionária, como pudemos perceber, é encantada com a liberdade pública, e tem medo da opressão política. A direita, aspira talvez, a um Estado justo embora imperfeito e não acredita num estado de liberdade sem limitações legais.

A extensão deste artigo me impede de cumprir o que prometi. Não poderei levantar as referências em Freud e Lacan acerca do tema da revolução, do socialismo ou do individualismo. É meu próximo projeto.

\section{Notas:}

${ }^{1}$ Este é um ensaio que deve servir de guia para discussão em meu seminário de março-julho de 2017, no Programa de Pós-graduação em Teoria Psicanalítica da Universidade Federal do Rio de Janeiro (UFRJ).

${ }^{2}$ Coelho dos Santos, T. (2012). Existe uma nova doutrina da ciência na psicanálise de orientação lacaniana? De que real se trata na clínica psicanalítica. Rio de Janeiro: Cia de Freud.

${ }^{3}$ Cf. O real da ciência e o real na prática do psicanalista. Projeto de Pesquisa financiado com Bolsa de Produtividade nível 1C do CNPq (2014/2018), em andamento.

${ }^{4} \mathrm{O}$ uso moderno do termo esquerda surgiu na Assembleia dos Estados Gerais de 1789, quando a nobreza se sentou à direita do rei e o Terceiro Estado à esquerda.

${ }^{5}$ Alain é o pseudônimo de Émile Auguste-Chartier (1868 -1951), filósofo, jornalista e pacifista francês.

${ }^{6}$ Adams, J. (1765). Dissertation on the Canon and the feudal law, vol. III. EUA: Boston Gazette, p. 452.

${ }^{7}$ Condorcet (1847-1849). Sur le mot révolutionnaire, Oeuvres, vol XII. Paris.

${ }^{8}$ Depois do assassinato do pai, os filhos descobrem que o pai odiado era também amado. Esta dimensão do remorso, da dívida simbólica que aparece somente depois do ato, reintroduz o amor, recalcando a violência.

${ }^{9}$ Cf. Toqueville, A. apud Arendt, H. (2016). Sobre a Revolução. São Paulo: Companhia das Letras.

\section{Referências Bibliográficas}

Arendt, H. (2012). Origens do Totalitarismo. São Paulo: Companhia das Letras.

Arendt, H. (2016). Sobre a Revolução. São Paulo: Companhia das Letras.

Aron, R. (2016). O ópio dos intelectuais. São Paulo: Três Estrelas.

Coelho dos Santos, T. (2001). Quem precisa de análise hoje? São Paulo: Bertrand Brasil.

Coelho dos Santos, T. (2004a). Le sacré dans la gauche et dans la pratique lacanienne. Lettre Mensuelle de l'École de la Cause Freudienne, (233), 1-32. Paris: ECF. 
Coelho dos Santos, T. (2004b). O que não tem remédio remediado está! Revista Latinoamericana de Psicopatologia Fundamental, 7(1), 63-74.

Coelho dos Santos, T. (2005a). A prática lacaniana na civilização sem bússola. In Coelho dos Santos, T. (Org.). Efeitos terapêuticos na psicanálise aplicada (pp. 61-92). Rio de Janeiro: Contracapa. Coelho dos Santos, T. (2005b). Sinthoma: corpo e laço social. Rio de Janeiro: Sephora/UFRJ.

Coelho dos Santos, T. (2005c). A psicopatologia psicanalítica de Freud à Lacan. Revista Pulsional de Psicanálise, 18(183), 74-81. São Paulo: Escuta.

Coelho dos Santos, T. (2005d). Sintoma e sexuação: insígnia ou caráter? Latusa - Revista de Psicanálise da Escola Brasileira de Psicanálise - Seção Rio de Janeiro, (10), 37-53. Rio de Janeiro: EBP.

Coelho dos Santos, T. \& Antunes, M. C. C. (2006). Se todo gordo é feliz, a obesidade é um sintoma ou uma solução? In Bastos, A. (Org.). Psicanalisar hoje. Rio de Janeiro: Contracapa.

Coelho dos Santos, T. \& Sartori, A. P. (2007a). Loucos de amor! Neuroses narcísicas, melancolia erotomania feminina. Tempo psicanalítico, (39), 13-34. Rio de Janeiro: SPID.

Coelho dos Santos, T. \& Zucchi, M. A. (2007b). Estrutura e gozo: os novos sintomas como solução na neurose e na psicose. In Freire, A. B. (Org.). Apostar no sintoma (pp. 61-82). Rio de Janeiro: Contracapa.

Coelho dos Santos, T. (2010, out.). Lá onde o inconsciente falassério, o real morre de rir. Opção Lacaniana - Revista Brasileira Internacional de Psicanálise, (58), 147-159. São Paulo: Eólia.

Coelho dos Santos, T. (2010, nov. a 2011, abr.). A dimensão real da inserção na ordem simbólica. aSEPHallus - Revista Eletrônica do Núcleo Sephora, 6(11), 1-17. Recuperado de: http://www.isepol.com/asephallus/numero_11/artigo_01_revista11.html.

Coelho dos Santos, T. (2011, nov. a 2012, abr.). Sobre o real sem sentido nas ciências em geral e na psicanálise em particular. Revista aSEPHallus de Orientação Lacaniana, 11(22), 12-28. Recuperado de http://www.isepol.com/asephallus/numero 13/artigo 01.html.

Coelho dos Santos, T. (2011). A materialidade da letra e o realismo da estrutura na psicanálise de orientação lacaniana. In Lo Bianco, C. (Org.). A materialidade da psicanálise. Rio de Janeiro: Contracapa.

Coelho dos Santos, T. (2012). Existe uma nova doutrina da ciência na psicanálise de orientação lacaniana? In Coelho dos Santos, T.; Martello, A. \& Santiago, J. (Orgs.). De que real se trata na clínica psicanalítica? Psicanálise, ciência e discursos da ciência (pp. 35-61). Rio de Janeiro: Cia de Freud.

Coelho dos Santos, T. (2012, mai. a out.). O lugar certo onde colocar o desejo do analista na era dos direitos. Revista aSEPHallus de Orientação Lacaniana, 714), 14-26. Recuperado de http://www.isepol.com/asephallus/numero 14/artigo 01.html.

Coelho dos Santos, T. \& Lopes, R. G. (2013). Psicanálise, ciência e discurso. Rio de Janeiro: Cia. de Freud. 
Coelho dos Santos, T. (2006). O psicanalista é um sinthoma. Latusa - Revista de Psicanálise da Escola Brasileira de Psicanálise - Seção Rio de Janeiro, (11), 57-72. Rio de Janeiro: EBP.

Coelho dos Santos, T. (2006). A ciência e a verdade na formação do analista lacaniano. Acheronta, (11). Buenos Aires: PsicoMundo.

Coelho dos Santos, T. (2008). Finais de análise: sexuação e invenção. Tempo psicanalítico, (40), 105-120. Rio de Janeiro: SPID.

Coelho dos Santos, T. (2008). Entre tapas e beijos: a tragicomédia dos sexos. Latusa - Revista de Psicanálise da Escola Brasileira de Psicanálise - Seção Rio de Janeiro, (13). Rio de Janeiro: EBP. Coelho dos Santos, T. (2008a). A política do psicanalista: o saber da psicanálise entre ciência e religião. Psicologia em Revista, 14(1), 63-82. Belo Horizonte: PUC-MG.

Coelho dos Santos, T. (2008b). Ciência e clínica psicanalítica: sobre o estruturalismo. Estudos Lacanianos, 1(1), 187-199. Belo Horizonte: Programa de Pós-graduação em Psicologia e do Laboratório de Psicanálise da Universidade Federal de Minas Gerais.

Coelho dos Santos, T. (2009). Sinthoma: a arte de encarnar e sublimar o próprio sexo. In Coutinho Jorge, M. A. e Mello de Lima, M. (Orgs.). Saber fazer com o real: diálogos entre Psicanálise e Arte. Rio de Janeiro: Companhia de Freud, PGPSA/IP/UERJ.

Coelho dos Santos, T. (2009). Não existe pecado do lado de baixo do equador? Cadernos de Psicanálise, 25(28), 121-142. Rio de Janeiro: Sociedade de Psicanálise da Cidade do Rio de Janeiro.

Coelho dos Santos, T. (2009). Semblante e discurso: estrutura e verdade na ciência e na psicanálise. Latusa - Revista da Escola Brasileira de Psicanálise - Seção Rio de Janeiro, (14). Rio de Janeiro: EBP.

Coelho dos Santos, T. (2009). A interpretação analítica do sinthoma. In Nascimento, E. (Org.). Revista do Curso de Especialização da UFBA (pp. 161-175). Salvador: UFBA.

Coelho dos Santos, T. (2009). Sobre a clínica de orientação lacaniana: dos impasses da sexuação à invenção do parceiro-sinthoma. Ágora, (12), 9-26. Rio de Janeiro: PPGTP/UFRJ.

Coelho dos Santos, T. (2009). Do saber exposto ao saber suposto e retorno: ensino, pesquisa e transmissão da psicanálise. Opção Lacaniana - Revista brasileira internacional de psicanálise, (54), 83-94. São Paulo: Eólia.

Coelho dos Santos, T. (2009). Do desejo do analista ao analista parceiro-sinthoma. Curinga, (27). Belo Horizonte: EBP.

Coelho dos Santos, T. (2016, mai. a out.). Desmentido ou inexistência do Outro: a era da pósverdade. Revista aSEPHallus de Orientação Lacaniana, 11(22), 4-19. Recuperado de www.isepol.com/asephallus. doi: 10.17852/1809-709x.2019v11n22p04-19.

Coelho dos Santos, T. (2016). O Outro que não existe: verdade verídica, verdades mentirosas e desmentidos veementes. Ágora, (19), 565-582. Rio de Janeiro: PPGTP/UFRJ. 
Freud, S. (1974). Totem e tabu. In J. Salomão (Trad.). Edição Standard Brasileira das Obras Psicológicas Completas de Sigmund Freud (Vol. XIII, pp. 13-197). Rio de Janeiro: Imago (Trabalho original publicado em 1913).

Foucault, M. (1977). A história da sexualidade I, A vontade de saber. Rio de Janeiro: Graal Ed.

Lacan, J. (1998). Kant com Sade. In V. Ribeiro (Trad.) Escritos. Rio de Janeiro: Zahar (Trabalho original publicado em 1966).

Lacan, J. (1998). O seminário, livro 7: a ética da psicanálise. Rio de Janeiro: Zahar (Trabalho original publicado em 1959-1960).

Hobsbawm, E. (1962). A era das revoluções. São Paulo: Cia das Letras.

Hobsbawm, E. (1994). A era dos extremos. São Paulo: Cia das Letras.

Hobsbawm, E. (2003). Revolucionários - Ensaios contemporâneos. São Paulo: Paz \& Terra.

Scruton, R. (2014). Pensadores da Nova Esquerda. São Paulo: É realizações.

Citacão/Citation: Coelho dos Santos, T. (nov. 2016 a abr. 2017). A psicanálise é politicamente revolucionária ou conservadora? Revista aSEPHallus de Orientação Lacaniana, 12(23), 4-22. Disponível em www.isepol.com/asephallus. doi: 10.17852/1809-709x.2019v12n23p4-22.

Editor do artigo: Tania Coelho dos Santos.

Recebido/Received: 24/01/2017 / 01/24/2017.

Aceito/Accepted: 14/02/2017 / 02/14/2017.

Copyright: (C) 2013 Associação Núcleo Sephora de Pesquisa sobre o moderno e o contemporâneo. Este é um artigo de livre acesso, que permite uso irrestrito, distribuição e reprodução em qualquer meio, desde que o autor e a fonte sejam citados/This is an open-access article, which permites unrestricted use, distribution, and reproduction in any medium, provided the author and source are credited. 